\title{
Mean Carotid Intima-Media Thickness in Patients with Type 2 Diabetes Mellitus Attending Tertiary Care Center: A Descriptive Cross-sectional Study
}

Prakash Kayastha, 'Sharma Paudel,' Ghanshyam Gurung, ${ }^{1}$ Pradeep Kumar, ${ }^{1}$ Rudra Prasad Upadhyaya, ${ }^{2}$ Sasmita Tuladhar, ${ }^{3}$ Govinda Adhikari, ${ }^{2}$ Santosh Maharjan ${ }^{2}$

'Department of Radiology and Imaging, Maharajguni Medical Campus, Tribhuvan University Teaching Hospital, Institute of Medicine, Maharaigunj, Kathmandu, Nepal, 'Department of Radiology and Imaging, Grande International Hospital, Dhapasi, Kathmandu, Nepal, 'BDepartment of Radiology and Imaging, Kanti Children's Hospital, Maharaiguni, Kathmandu, Nepal.

\section{ABSTRACT}

Introduction: Sonographic carotid intima media thickness measurement in diabetic patients is an important tool for estimating the risk of cardiovascular and cerebrovascular events. It is a simple, noninvasive and widely available tool which can give idea of further treatment needed. The objective of this study was to determine the mean intima media complex thickness in patients with type II diabetes mellitus attending a tertiary care center.

Methods: This was a descriptive cross-sectional study done in 64 patients with the type II diabetes mellitus patients visiting diabetic clinic of Tribhuvan University Teaching Hospital, sent for carotid Doppler examination in the department of radiology and imaging. Ethical approval was taken from the Instituitonal Review Board. Convenient sampling method was used. Carotid intima media thickness was measured on both sides and mean intima media thickness was calculated. Mean intima media thickness for male and female diabetic patients was also calculated separately. Statistical Package for Social Sciences version 25 was used for data analysis.

Results: The mean carotid intima media thickness was $0.86 \pm 0.13 \mathrm{~mm}$ with range from $0.7 \mathrm{~mm}$ to $1.3 \mathrm{~mm}$. Mean intima media thickness in male was $0.832 \pm 0.094 \mathrm{~mm}$ and in female it was $0.904 \pm 0.144 \mathrm{~mm}$. Among 64 patients, 30 (46.8\%) were female and 34 (53.3\%) were male. Age of the patients ranged from 35 years to 68 years with mean age of $52.4 \pm 6.54$ years.

Conclusions: Carotid intima media thickness in patients with type II diabetes mellitus showed higher values than that of mean value from study done in similar study. Female had higher mean intima media thickness than male.

Keywords: atherosclerosis; carotid intima media thickness; diabetes mellitus type 2.

\section{INTRODUCTION}

Sonographic evaluation of carotid artery intimamedia thickness (CIMT) is a simple, noninvasive, widely available and reproducible imaging parameter. Intima-media thickness (IMT) is an early marker of atherosclerosis, independent predictor of cardiovascular and cerebrovascular disease and also used for effectiveness of medical therapies in treating atherosclerosis. Noninvasive techniques such as B-mode ultrasound can directly assess the IMT, which corresponds to the thickness of the histologic intima and media. ${ }^{1-3}$
Diabetes mellitus (DM) is considered a disease which accelerates atherosclerotic changes. IMT is considered to correlate well with the duration of diabetes and various parameters associated with it..$^{4-7}$

Patients with type-2 diabetes mellitus have greater

Correspondence: Dr. Sharma Paudel, Department of Radiology and Imaging, Maharajguni Medical Campus, Tribhuvan University Teaching Hospital, Institute of Medicine, Maharajguni, Kathmandu, Nepal. Email: sharmapaudel@ gmail.com, Phone: +977-9841393486. 
Paudel et al. Mean Carotid Intima-Media Thickness in Patients with Type 2 Diabetes Mellitus Attending Tertiary Care...

carotid intima media thickness. ${ }^{8}$ IMT measurement should be included as a diagnostic tool, given the paucity of facilities for invasive techniques in Nepal. This may help in early identification of coronary artery disease.

The aim of this study was to find out the mean CIMT in type II diabetic patients attending a tertiary care center.

\section{METHODS}

This was a descriptive cross-sectional study done in patients with type 2 Diabetes mellitus visiting the diabetic clinic of Tribhuvan University Teaching Hospital (TUTH) and patients visiting the Department of Radiology and Imaging for carotid Doppler examination.

An ethical clearance had been obtained from the institutional review committee of the Institute of Medicine, Maharajgunj. The study duration was one year from September 2019 to September 2020. Convenient sampling method was used. Patients with Type 2 Diabetes Mellitus (both newly diagnosed and old cases), patients aged more than 25 years and both sexes were included in the study. Type 1 diabetic, uncontrolled type 2 diabetic and patient $<25$ years were not included in this study.

Sample size was calculated by using following formula:

$$
\begin{aligned}
\mathrm{n} & =\mathrm{Z}^{2} \times \sigma^{2} / \mathrm{e}^{2} \\
& =(1.64)^{2} \times(0.5)^{2} /(0.11)^{2} \\
& =56
\end{aligned}
$$

Where

$\mathrm{n}=$ minimum number of sample required

$\mathrm{Z}=1.64$ at $90 \%$ Confidence Interval $(\mathrm{Cl})$

$\sigma=$ standard deviation taken from the previous study

$\mathrm{e}=$ margin of error, $11 \%$

From the above mentioned formula minimum sample required for the study was calculated to be 56 . We enrolled 64 patients in our study. Convenient sampling method was used to collect sample.

The common and internal carotid arteries of both sides were evaluated sonographically, using high frequency linear probe $(7-12 \mathrm{MHz})$ of Samsung Medison Accuvix A30 ultrasound machine, with the patient in supine position and the examiner seated near the patient's head. The patient's head was tilted away from the side being examined facilitating the neck exposure. With this technique, two parallel echogenic lines separated by an anechoic space can be visualized at the artery wall. These lines are generated by the blood-intima and media-adventitial interfaces. The distance between the two lines gives a reliable index of the thickness of the intimal-media complex. ${ }^{9}$ The IMT of the common and internal carotid arteries was measured within one $\mathrm{cm}$ of the carotid bulb. IMT of only the plaque-free segments was recorded.

A total of eight IMT values were taken from different sites including the near and far walls of common and internal carotid arteries on both sides: the near and far wall of the proximal $8 \mathrm{~mm}$ of the internal carotid artery, the near and far wall of the carotid bifurcation beginning at the tip of the flow divider and extending 8 $\mathrm{mm}$ proximally, and the near and far wall of the arterial segment extending 8 to $16 \mathrm{~mm}$ proximally to the tip of the flow divider into the common carotid artery. ${ }^{10}$ Average values of these measurements for each participant was calculated to find out the mean IMT.

The mean value of the above was obtained and designated as the mean IMT value of that subject as follows:

(RCN: Near wall of Right CCA, RCF: Far wall of right CCA, RIN: Near wall of right ICA, RIF: Far wall of right ICA, LCN: Near wall of left CCA, LCF: Far wall of left CCA, LIN: Near wall of left ICA, LIF: Far wall of left ICA).

Data was entered in Microsoft excel and analysis was carried out using Statistical Package for Social Sciences (SPSS) version 25 and mean values for the numerical variables were calculated.

\section{RESULTS}

The mean intima media thickness is $0.86 \pm 0.12 \mathrm{~mm}$. The mean IMT values ranged from $0.70 \mathrm{~mm}$ to $1.3 \mathrm{~mm}$ with median of $0.85 \mathrm{~mm}$ and. Mean IMT value in male patients was found to be $0.832 \pm 0.094 \mathrm{~mm}$ and in female it was found to be $0.904 \pm 0.144 \mathrm{~mm}$. The values of IMT in females were higher than those of males.

Out of the 64 patients, $30(46.8 \%)$ were female and 34 (53.3\%) were males (Table 1 ).

\begin{tabular}{|ll|}
\hline Table 1. Gender wise distribution. \\
\hline Gender & $\mathbf{n}(\%)$ \\
Male & $34(53.30)$ \\
Female & $30(46.80)$ \\
\hline
\end{tabular}

The age of the participants ranged from 35 years to 68 years with mean age of 52.41 , median age of 52 years (variance 42.848, standard deviation 6.546) (Figure 1). 
Paudel et al. Mean Carotid Intima-Media Thickness in Patients with Type 2 Diabetes Mellitus Attending Tertiary Care...

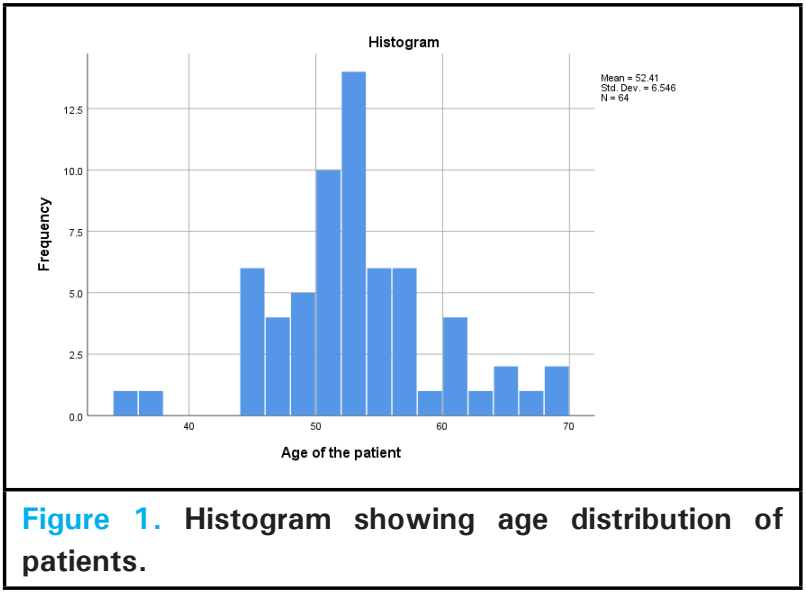

DISCUSSION

In this study we measured carotid intima media thickness in 64 type II diabetes patients. The mean thickness was $0.86 \pm 0.12 \mathrm{~mm}$. Mean carotid intima media thickness from this study in type II diabetes patients was higher than that of mean thickness from the study in normal population by Paul $\mathrm{J}$, et al. and Randrianarisoa E, et al. ${ }^{11,12}$ Increase in carotid intima media thickness in patients with type II diabetes is shown in study done by Kota SK, et al. and Paul $\mathrm{J}$, et al. which is consistent with this study. ${ }^{13,14}$ The rate of change in IMT with age has been calculated to be about $0.01 \mathrm{~mm} /$ year in the general population and $0.03-0.06 \mathrm{~mm} /$ year in patients with coronary artery disease. ${ }^{15}$ Type II diabetes is considered as a risk factor for coronal artery disease and ultrasonography as a reliable and accurate technique to determine IMT in the superficial arteries. Thus, carotid IMT measurement and peripheral plaque detection by using $B$ mode ultrasound is of clinical value in the screening of patients with coronary artery disease. ${ }^{1,16,17}$

Mean IMT in this study showed higher values in female than that of male which was similar to that of study that was carried out by Zakaria M, et al. Mean IMT in females was higher than that in males in the study $\left(0.90 \mathrm{~mm}\right.$ in males and 0.91 in females). ${ }^{7}$ However studies carried out by Baba, et al. showed similar intima media thickness values in male and female population. ${ }^{13}$ While other studies carried out by Pujia A, et al. and Theodora S, et al. showed male patients to have higher intima media thickness than females. ${ }^{14,15}$ This discrepancy in literature requires further investigations on this field.

Few limitations of the study are worth mentioning. Measurements were difficult in obese and short necked individuals, especially for measuring the intima media thickness of internal carotid arteries. There was difficulty in visualizing the intima media thickness due to near field artifacts in some cases.

\section{CONCLUSIONS}

Carotid intima media thickness measured in patients with type II diabetes mellitus were higher than that of mean value from study done in similar study. Increased intima media thickness is considered a risk factor for cardiovascular and cerebrovascular events. Examination with ultrasound which is a safe, non-invasive and widely available tool, can predict the occurrence of these events so that they can be prevented by timely intervention. From the study, routine and timely evaluation of carotid intima- media thickness is strongly recommended.

\section{Conflict of Interest: None.}

\section{REFERENCES}

1. Jadhav UM, Kadam NN. Carotid intima-media thickness as an independent predictor of coronary artery disease. Indian Heart J. 2001 Jul-Aug;53(4):458-62. [PubMed]

2. O'Leary DH, Polak JF, Kronmal RA, Savage PJ, Borhani NO, Kittner SJ, et al. Thickening of the carotid wall. A marker for atherosclerosis in the elderly? Cardiovascular Health Study Collaborative Research Group. Stroke. 1996 Feb;27(2):224-31. [PubMed | Full Text $\mid \underline{\text { DOI] }}$

3. Baldassarre D, Amato M, Bondioli A, Sirtori CR, Tremoli E. Carotid artery intima-media thickness measured by ultrasonography in normal clinical practice correlates well with atherosclerosis risk factors. Stroke. 2000 Oct;31(10):2426-30. [ PubMed | Full Text | DOI]

4. Oygarden H. Carotid Intima-Media Thickness and Prediction of Cardiovascular Disease. J Am Heart Assoc. 2017 Jan 21;6(1):e005313. [uuMed | Full Text | DOI]

5. Lee EJ, Kim HJ, Bae JM, Kim JC, Han HJ, Park CS, et al.
Relevance of common carotid intima-media thickness and carotid plaque as risk factors for ischemic stroke in patients with type 2 diabetes mellitus. AJNR Am J Neuroradiol. 2007 May;28(5):916-9. [ PubMed | Full Text]

6. Robertson CM, Gerry F, Fowkes R, Price JF. Carotid intima-media thickness and the prediction of vascular events. Vasc Med. 2012 Aug;17(4):239-48. [PubMed | Full Text | $\underline{\mathrm{DOI}}]$

7. Butt MU, Zakaria M. Association of common carotid intimal medial thickness (CCA-IMT) with risk factors of atherosclerosis in patients with type 2 diabetes mellitus. J Pak Med Assoc. 2009 Sep;59(9):590-3. [PubMed | Full Text]

8. Al-Nimer MS, Hussein II. Increased mean carotid intima media thickness in type 2 diabetes mellitus patients with non-blood pressure component metabolic syndrome: A preliminary report. Int J Diabetes Dev Ctries. 2009 Jan;29(1):19-22. [PubMed | Full Text | DOI] 
Paudel et al. Mean Carotid Intima-Media Thickness in Patients with Type 2 Diabetes Mellitus Attending Tertiary Care...

9. Pignoli P, Tremoli E, Poli A, Oreste P, Paoletti R. Intimal plus medial thickness of the arterial wall: a direct measurement with ultrasound imaging. Circulation. 1986 Dec;74(6):1399-406. [PubMed | Full Text | DOI]

10. Espeland MA, Craven TE, Riley WA, Corson J, Romont A, Furberg CD. Reliability of longitudinal ultrasonographic measurements of carotid intimal-medial thicknesses. Asymptomatic Carotid Artery Progression Study Research Group. Stroke. 1996 Mar;27(3):480-5. [PubMed | Full Text | DOI]

11. Paul J, Shaw K, Dasgupta S, Ghosh MK. Measurement of intima media thickness of carotid artery by B-mode ultrasound in healthy people of India and Bangladesh, and relation of age and sex with carotid artery intima media thickness: An observational study. J Cardiovasc Dis Res. 2012 Apr;3(2):128-31. [ubMed | Full Text]

12. Randrianarisoa E, Rietig R, Jacob S, Blumenstock G, Haering $\mathrm{HU}$, Rittig K, et al. Normal values for intima-media thickness of the common carotid artery--an update following a novel risk factor profiling. Vasa. 2015 Nov;44(6):444-50. [PubMed | Full Text | DOI]

13. Kota SK, Mahapatra GB, Kota SK, Naveed S, Tripathy PR, Jammula $S$, et al. Carotid intima media thickness in type 2 diabetes mellitus with ischemic stroke. Indian J Endocrinol Metab. 2013 Jul;17(4):716-22. [PubMed | Full Text]

14. Paul J, Shaw K, Dasgupta S, Ghosh MK. Measurement of intima media thickness of carotid artery by B-mode ultrasound in healthy people of India and Bangladesh, and relation of age and sex with carotid artery intima media thickness: An observational study. J Cardiovasc Dis Res. 2012 Apr;3(2):128-31. [PubMed | Full Text | DOI]

15. Lehmann ED, Riley WA, Clarkson P, Gosling RG. Non-invasive assessment of cardiovascular disease in diabetes mellitus. Lancet. 1997 Jul;350 Suppl 1:SI14-9. [PubMed | Full Text | DOI]

16. Hulthe J, Wikstrand J, Emanuelsson H, Wiklund $\mathrm{O}$, de Feyter PJ, Wendelhag I. Atherosclerotic changes in the carotid artery bulb as measured by B-mode ultrasound are associated with the extent of coronary atherosclerosis. Stroke. 1997 Jun;28(6):1189-94. [라Med | Full Text | DOI]

17. Kallikazaros I, Tsioufis C, Sideris S, Stefanadis C, Toutouzas P. Carotid artery disease as a marker for the presence of severe coronary artery disease in patients evaluated for chest

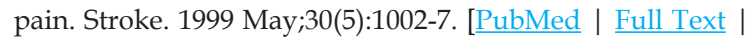
DOI]

18. Baba M, Talle M, Ibinaiye P, Abdul H, Buba F. Carotid intima-media thickness in patients with diabetes mellitus attending tertiary care hospital in Nigeria. Angiol. 2018;6(210):2. [․ㅏll Text | DOI]

19. Pujia A, Gnasso A, Irace C, Colonna A, Mattioli PL. Common carotid arterial wall thickness in NIDDM subjects. Diabetes Care. 1994 Nov;17(11):1330-6. [PubMed | DOI]

20. Temelkova-Kurktschiev TS, Koehler C, Leonhardt W, Schaper F, Henkel E, Siegert G, et al. Increased intimal-medial thickness in newly detected type 2 diabetes: risk factors. Diabetes Care. 1999 Feb;22(2):333-8. [ubMed | Full Text | DOI]

This work is licensed under a Creative Commons Attribution 4.0 International License. The images or other third party material in this article are included in the article's Creative Commons license, unless indicated otherwise in the credit line; if the material is not included under the Creative Commons license, users will need to obtain permission from the license holder to reproduce the material. To view a copy of this license, visit http://creativecommons.org/licenses/by/4.0/ 